after endoscopic stone extraction. Surg Endosc. 2006; 20:1594-9.

3 . Kibria SM, Hall R. Recurrent bile duct stones after transduodenal sphincteroplasty. HPB (Oxford). 2002;4:63-6.

4. Rizzutti, RP, McElwee TB, Carter JW. Choledochoduodenostomy. A safe and efficacious alternative in the treatment of biliary tract disease. Am Surg. 1987; 53:22-5.

5. Caroli-Bosc FX, Demarquay JF, Peten EP, Dumas R, Bourgeon A, Rampal P, et al. Endoscopic management of sump syndrome after choledochoduodenostomy: retrospective analysis of 30 cases. Gastrointest Endosc. 2000; 51 :180-3.

\section{Gastric teratoma: unusual location and difficulties in diagnosis}

\section{Introduction}

Gastric teratoma is an extremely rare neoplasm with only about 112 cases reported in the literature. ${ }^{1}$ These tumors usually present as exophytic masses with symptoms of obstruction and upper gastrointestinal bleeding., ${ }^{2,3}$ The clinical symptoms combined with the CT scan images usually allow for a reasonably definite pre-operative diagnosis. We report a case of gastric teratoma with no clinical indication of gastric origin. The only clue to diagnosis, in retrospect, was the mass being more anteriorly placed than expected in the CT scan images.

\section{Case report}

A 2-year-old child presented with history of a non-progressive lump in the abdomen since birth. This was accompanied by occasional colicky abdominal pain that settled spontaneously in a few minutes. There was no history of hematemesis, vomiting, early satiety or poor acceptance of feeds. Physical examination revealed fullness of the upper and central abdomen with a large palpable $16 \times 10 \mathrm{~cm}$ mass. The mass was non-tender, had an irregular surface and a variable consistency. The mass was not mobile along any axis. Based on these findings a provisional clinical diagnosis of a retroperitoneal mass, possibly a teratoma, was made. Ultrasonography revealed a large multiseptate, midline cystic mass with a soft tissue component.

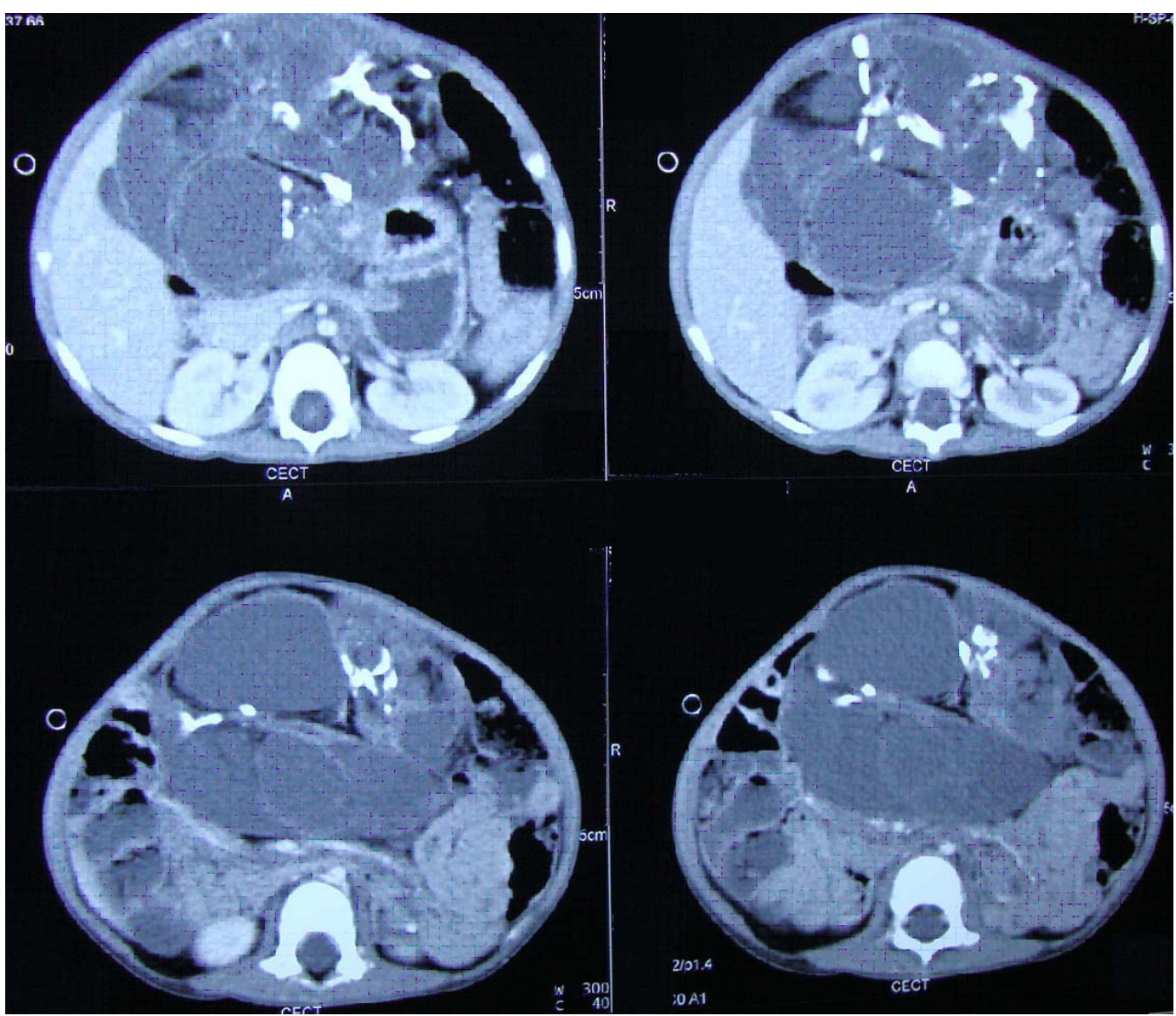

Figure 1: CECT showing a heterogenous mass with foci of calcification and soft tissue. The mass was seen to be placed anterior to the pancreas and superior mesenteric vessels. 


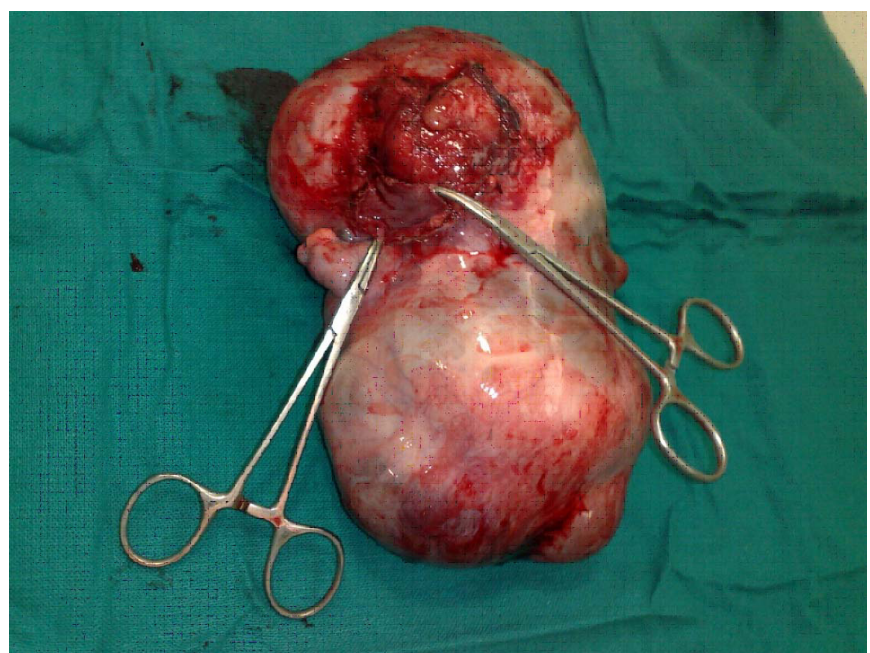

Figure 2: Resected teratoma with the part of stomach wall from which it was arising held in forceps.

A CECT scan of the abdomen revealed a $15 \times 12 \mathrm{~cm}$ cystic mass with areas of calcification and fat and soft tissue intensities,suggestive of a retroperitoneal teratoma (Figure 1). However, a few features that were unusual for a retroperitoneal teratoma included a large area of contact with the stomach wall and the pancreas and superior mesenteric vessels were seen posterior to the mass. There was no intra-luminal extension of the mass.

An exploratory laparotomy revealed a large, nodular mass with variable consistency, displacing bowel loops laterally. After careful mobilization the mass was found to be arising from the anterior wall of the stomach near the lesser curvature. There was neither any intra-luminal content nor a retroperitoneal extension. The mass was removed along with a sleeve of the stomach and the defect was repaired primarily in two layers (Figure 2).

The post-operative period was uneventful. Histopathology examination confirmed the diagnosis of a mature gastric teratoma.

\section{Discussion}

Gastric teratomas are rare tumors comprising approximately $1 \%$ of all teratomas and $1.6 \%$ of all abdominal teratomas. ${ }^{1,4}$ The first case was reported in 1922 by Eustermann and Sentry. ${ }^{5}$ It is more commonly found in the males with only a few cases reported in females. ${ }^{6}$ The most common site for a teratoma is the sacrococcygeal region followed by gonads, mediastinum and retroperitoneum. ${ }^{?}$

The usual presentation of a gastric teratoma include an abdominal lump, hematemesis or melena and abdominal pain with vomiting and dehydration, distension, anemia, poor feeding and failure to thrive. ${ }^{2,3,8}$ In contrast, retroperitoneal teratomas usually present as a mass with no gastrointestinal symptoms. Our patient presented simply with a non-progressive mass with no other symptoms to suggest itsgastric origin, thus giving no indication of it being a gastric mass. On examination it demonstrated no mobility as could be expected in a retroperitoneal mass. In retrospect, this finding was probably more due to the fact that the tumour was huge and occupying almost the entire abdominal cavity thus providing no space for mobility. The contrast enhanced CT was reported as a retroperitoneal tumor. In addition, retroperitoneal teratomas are more common than gastric teratomas. Thus, the diagnosis of retroperitoneal teratoma was the first clinical diagnosis. The only unusual feature on imaging was the anterior location of the mass in relation to the pancreas and the superior mesenteric vessels; this is not expected in retroperitoneal teratomas. However, some reports suggest that contrast enhanced CT is not very reliable in either assessing the organ of origin or the degree of adherence of the tumor to the adjacent organs. ${ }^{9,10}$ Hence, an exploratory laparotomy was performed with this conflicting evidence and it confirmed the origin of the teratoma from the lesser curvature of the stomach. Anterior wall, lesser curvature gastric teratomas are rare. They have usually been reported to arise from the greater curvature and the posterior wall. ${ }^{9}$ Thus the origin of this teratoma was from an unusual site in an uncommon organ.

N SUGANDHI ${ }^{1}$

AK GUPTA $^{2}$

V BHATNAGAR ${ }^{1}$

Correspondence: Dr. V Bhatnagar Departments of Pediatric Surgery ${ }^{l}$ and Radiodiagnosis, ${ }^{2}$ All India Institute of Medical Sciences, New Delhi - 110029, India

Email:veereshwarb@hotmail.com

\section{References}

1. Ukiyama E, Endo M, Yoshida F, Tezuka T, Kudo K, Sato S, et al. Recurrent yolk sac tumour following resection of a neonatal immature gastric teratoma. PediatrSurg Int. 2005;21:585-8.

2. Haley T, Dimler M, Hollier P. Gastric teratoma with gastrointestinal bleeding. J Pediatr Surg.1986;21:949-50.

3 Ratan SK, Kulshreshtha R. Immature gastric teratoma in an infant. Indian J Pediatr. 1999;36:847-9.

4. Hirugade ST, Deshpande AV, Talpallikar MC, Borwankar SS.Gastric teratoma : a rare cause of gastrointestinal bleeding. Indian J Gastroenterol. 2001;20:158-9.

5. Eustermann GB, Sentry EG. Benign tumours of the 
stomach.Report of 27 cases.Surg Gynecol Obstet. 1922;34:372-8.

6. Cairo MS, Grosfeld JL, Weatman RM. Gastric teratoma: unusual cause for bleeding of the upper gastrointestinal tract in the newborn. Pediatrics. 1981;67:721-4.

7. Göbel U, Calaminus G, Engert J, Kaatsch P, Gadner H, Bökkerink JP, et al. Teratomas in infancy and childhood. Med Pediatr Oncol. 1998;31:8-15.

8. Ratan KN, Mathur SK, Marwah N, Purwar P, Rohilla $\mathrm{S}$, Balasubramaniam G. Gastric teratoma. Indian J Pediatr. 2004;71:171-2.

9. Utsch B, Fleischhack G, Knopfle G, Hasan C, Bode U. Immature gastric teratoma of the lesser curvature in a male infant. J Pediatr Gastroenterol Nutr. 2001;32:204-6.

10. Chaudhary A, Misra S, Wakhlu A, Tandon RK, Wakhlu AK. Retroperitoneal teratomas in children.Indian J Pediatr. 2006:73:221-3.

\section{Indispensable utility of intra-arterial calcium stimulation and hepatic venous sampling in a $7 \mathrm{~mm}$ insulinoma with poor imaging localization}

\section{Introduction}

With an incidence between 1-4 cases per million population, insulinomas are very rare, though they are the most common functional neuroendocrine neoplasm of pancreatic origin. ${ }^{1}$ Tumor localization with calcium gluconate arterial stimulation with hepatic venous sampling (ASVS) for insulin has been shown in cases of unsatisfactory imaging or suspected tumors smaller than $1 \mathrm{~cm}$. The surgeon's goal is to cure the patient with minimal morbidity, and confidence in localization of the lesion is a means to this end. This case contributes to the literature by demonstrating the indispensable utility of calcium gluconate arterial stimulation with hepatic venous sampling in the definitive localization of a pancreatic insulinoma.

\section{Case report}

A 54-year-old female presented with recent history of frequent episodes of feeling sweaty, panicky, anxious and shaky. She reported waking up in the night with these symptoms and eating often provided relief. She denied loss of consciousness, confusion or recent hospital admissions. A review of symptoms was unremarkable save an unintentional 10 pound weight gain. Her family history was significant for exocrine pancreatic cancer in her father. Vital signs and physical exam were within normal limits.

Suspecting hypoglycemia, her workup revealed a random plasma glucose of $38 \mathrm{mg} / \mathrm{dL}$, serum insulin of $4.8 \mu \mathrm{U} / \mathrm{mL}$ (normal: 2.6-24.4 $\mu \mathrm{U} / \mathrm{mL}$ ) and serum pro-insulin of $75.6 \mathrm{pmol} / \mathrm{L}$ (normal: $<18.8 \mathrm{pmol} / \mathrm{L}$ ). Notably, serum sulfonylurea levels were not detected. A fasting glucose tolerance test demonstrated the following 9:00 am values: serum glucose $=61 \mathrm{mg} / \mathrm{dL}$, insulin $=$ $7.4 \mu \mathrm{U} / \mathrm{mL}$, pro-insulin $=58.3 \mathrm{pmol} / \mathrm{L}$ and C-peptide $=2.4 \mathrm{ng} /$ $\mathrm{mL}$ (normal: $0.8-3.1 \mathrm{ng} / \mathrm{mL}$ ). The 11:00 pm values were serum glucose $=50 \mathrm{mg} / \mathrm{dL}$, insulin $=4.2 \mu \mathrm{U} / \mathrm{mL}$, pro-insulin $=59.4$ $\mathrm{pmol} / \mathrm{L}$ and C-peptide $=2.7 \mathrm{ng} / \mathrm{mL}$.

Endoscopic ultrasound (EUS) revealed a poorly-defined hypo-echoic lesion in the pancreatic head approximately 10x9 $\mathrm{mm}$ in size FNA was non-diagnostic. CT scan with contrast poorly supported the EUS findings with minimal enhancement . To further localize the lesion, pre-operative hepatic venous sampling of insulin (Figure 1a) and pro-insulin (Figure 1b) levels at 30 second intervals following selective intra-arterial

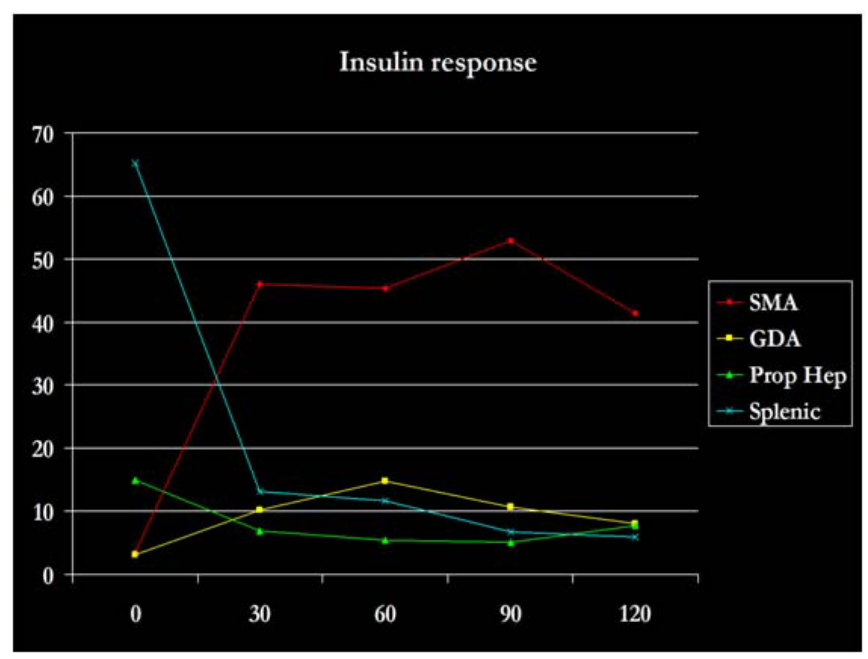

Figure 1: (a) Selective intra-arterial calcium gluconate injection and right hepatic vein sampling for insulin levels. Four separate calcium gluconate infusion trials were undertaken, each into a different artery: superior mesenteric artery (SMA), gastroduodenal artery (GDA), proper hepatic artery (Prop Hep) and splenic artery (splenic). Resultant insulin levels were recorded from right hepatic venous sampling at 30 second intervals until 120 seconds post-calcium stimulation. Note the exponential increase in insulin levels following calcium stimulation via the superior mesenteric artery from $<5 \mathrm{uU} /$ $\mathrm{mL}$ to $>45 \mathrm{uU} / \mathrm{mL}$ at $30 \mathrm{~s}$ and peaking $>50 \mathrm{uU} / \mathrm{mL}$ at $90 \mathrm{~s}$. Baseline to peak insulin increase is greater than 9-fold. 